\title{
A spectacular tumor response of a giant axillary mass treated with SABR in a palliative scenario
}

\author{
Uma resposta tumoral espetacular a uma massa axilar gigante tratada com SABR \\ em um cenário paliativo
}

Fernando Kojo Matsuura', Gustavo Viani Arruda', Leonardo Vicente Fay Neves' ${ }^{1}$, Alexandre Ciuffi Faustino', Ana Carolina Hamamura1', Anielle Freitas Bendo Danelichen ${ }^{1}$

\begin{abstract}
A 67-year-old male patient with a massive left axillary metastasis from an occult primary tumor (OPT) treated by stereotactic ablative radiotherapy (SABR) is presented. The patient had no clinical response to the initial chemotherapy treatment. Then, a SABR with a single fraction of 16Gy was performed. After SABR, a complete response was observed in the imaging exams after 3 months from the procedure. Currently, the patient is found with painfree, without any analgesic drug. The present case illustrates the importance of considering SABR in palliate care, even for a large tumor.
\end{abstract}

Keywords: Radiotherapy; Cancer; SABR; Oligometastasis.

\section{RESUMO}

Apresentamos um paciente do sexo masculino de 67 anos com uma metástase axilar esquerda maciça de um tumor primário oculto (TPO) que foi tratado com radioterapia estereotáxica ablativa (REA). O paciente não apresentou resposta clínica ao tratamento quimioterápico inicial. Em seguida, foi realizado uma REA com uma única fração de 16Gy. Após a REA, foi observada resposta completa nos exames de imagem após 3 meses do procedimento. Atualmente, o paciente encontra-se sem dor, sem nenhum analgésico. O presente caso ilustra a importância de considerar a REA no cuidado paliativo, mesmo para um tumor grande.

Descritores: Radioterapia; Câncer; REA; Oligometástases.

\footnotetext{
1.Hospital das Clínicas de Ribeirão Preto, Serviço de Radioterapia do Hospital das Clínicas de Ribeirão Preto - Ribeirão Preto - São Paulo - Brazil Financial support: none to declare.

Conflicts of interest: The authors declare no conflict of interest relevant to this manuscript.

Correspondence author: Fernando Kojo Matsuura

E-mail: fernandokm12@gmail.com
} 


\section{INTRODUCTION}

Occult primary tumors (OPT) can be defined as malignant neoplasms, whose primary site cannot be identified. Despite the technological advances in the pathological analysis with the incorporation of molecular and immunohistochemical studies in the last decades, the incidence of OPT remains stable, with about $5 \%$ of diagnosed cancers. ${ }^{(1)}$ Traditionally, the OPT is treated with chemotherapy of broad-spectrum, which generally produces a clinical response and prolongs survival.(2) Among the therapeutic arsenal to the management of the OPT, radiotherapy has a reduced role. It is considered as a palliative treatment commonly after several chemotherapy lines when the tumor is not responding, and the chances of controlling the disease are reduced. ${ }^{(3)}$

Stereotactic ablative radiotherapy (SABR) is a radiation technique that allows delivering a high-dose per fraction, with a strict margin and a deep fall-off the dose, sparing the surrounding healthy tissues of an excessive dose. ${ }^{(4)}$ Recently, SABR has gained notability and widespread use in the oligometastatic scenario. Several studies have reported a significant increase in the local control and improvement of survival with SABR. ${ }^{(4-7)}$ However, SABR is commonly employed to treat small tumors $(\angle 5 \mathrm{~cm})$ with limited experience of its use in large tumors $(>10 \mathrm{~cm})$. The importance of tumor size reduces SABR considerably as a treatment option in palliative care. To the best of our knowledge, there is no case report describing the role of SABR in the palliative care of a giant mass of an OPT. The intent in describing this case report is to show an outstanding clinical response of a giant axillary mass achieved with SABR in a patient with the OPT refractory to the chemotherapy treatment who required palliative radiotherapy.

\section{CASE REPORT}

In this case report, we present a 67-year-old male patient with a massive left axillary metastasis of $13 \mathrm{~cm}$ on the major axis (Figure 1). The immunohistochemistry panel from biopsy suggested a clear cell carcinoma. In the additional workup, no renal tumor or other primary site was found. At the diagnostic, the patient had complaints such as severe pain (10/10 points) and constant bleeding by the axillary mass. Chemotherapy with carboplatin and paclitaxel was initiated without any clinical response after 2 cycles.

The patient was simulated in computerized tomography (CT) on the supine position with the arm slightly elevated and open. A vac-loc cushion was molded to guarantee positioning and daily reproduction. The CT slices of $1 \mathrm{~mm}$ were acquired from the top of the cranium until the second lumbar spinal vertebra. The gross tumor volume (GTV) was considered the axillary mass, and no clinical target volume was adopted. The planning volume treatment (PTV) was generated from GTV with a margin of $5 \mathrm{~mm}$ in all directions. A dose equivalent to 60Gy with a $2 \mathrm{~Gy}$ fraction was chosen. Thus, a single dose fraction of 16Gy was delivered to cover $95 \%$ of PTV, respect all the restriction doses of the organs at risk: lung (V5$20 \%$ ), brachial plexus (Dmax $<16 \mathrm{~Gy}$ ), and chest wall (Dmax<16Gy). The intensity-modulated radiotherapy (IMRT) with $x x$ fields was used. The patient tolerated the treatment very well without any intercurrence. After treatment, the patient was followed one week, 1, 3, and 6 months later, with clinical exam and CT. In the follow-up, the only toxicity observed was grade 2-skin toxicity. The tumor had an extraordinary response disappearing entirely after 3 months from SABR (Figure 2). Currently, the patient is found pain-free, with no opioid, analgesic consumption, or
(A)

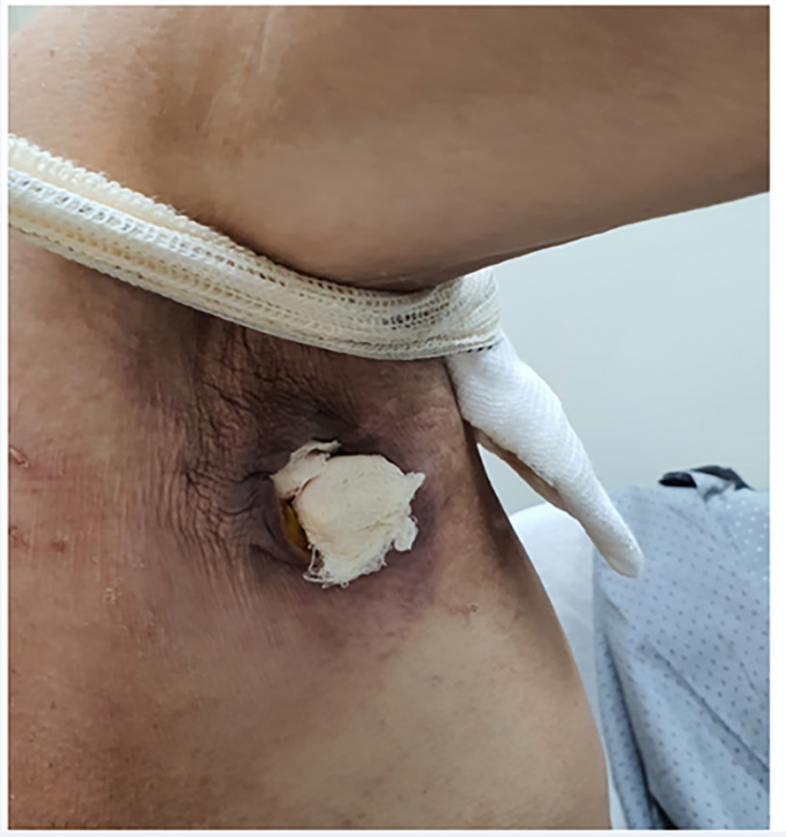

(B)

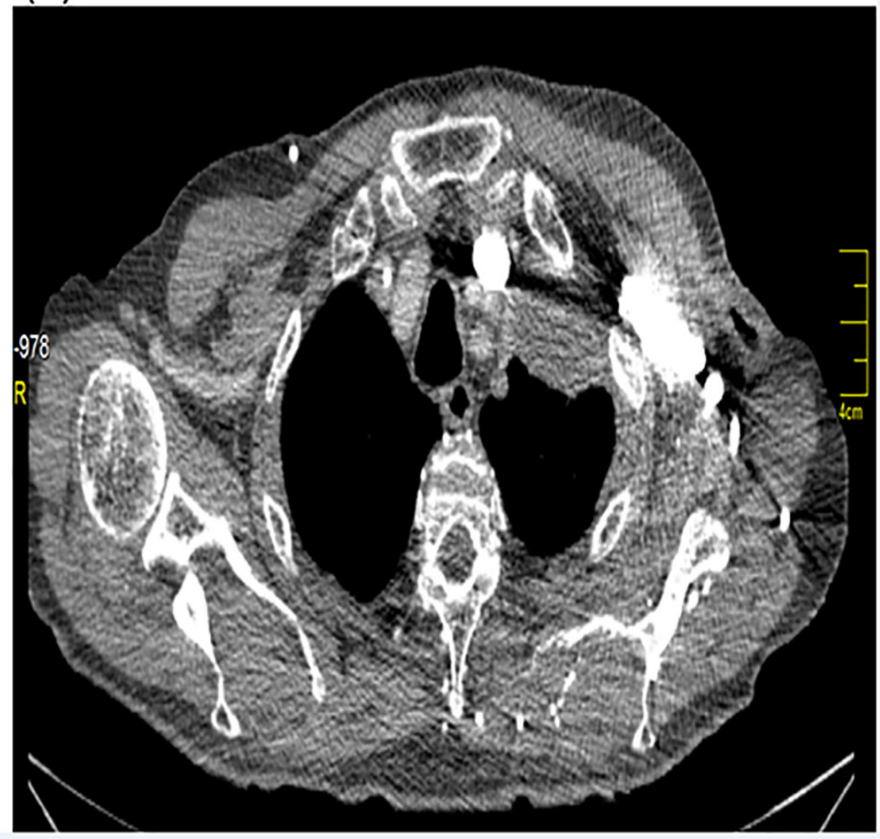

Figure 1. Complete response after 3 months from SABR. 
(A)

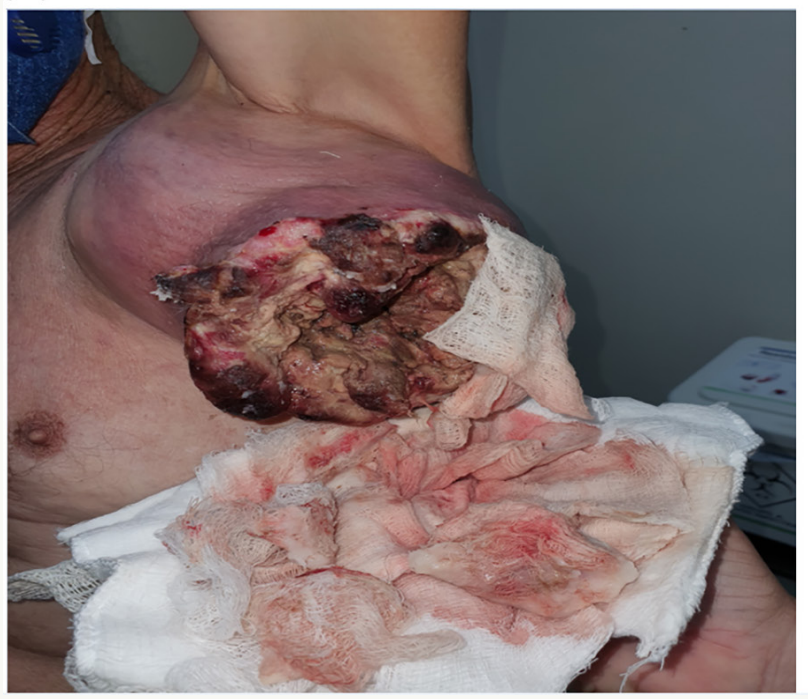

Figure 2. massive metastatic axillary lesion pretreatment.

bleeding, and sleeping well. The complete sustained response at the irradiated site remains, and the patient report significantly better quality of life after 6 months from the SABR.

\section{DISCUSSION}

Stereotactic ablative radiotherapy (SABR) proved to be an effective therapeutic modality. It is capable of producing a high-rate of local control independently of the tumor histology, while it is incredibly convenient due to the short treatment course. Toxicities found in this approach do not differ from conventional treatment, with the majority of patients having mild symptoms. ${ }^{(4)}$

Ablative radiotherapy alone as definitive treatment has been poorly investigated in palliative care. The use of radiotherapy for the OPT available in the literature is limited to traditional radiotherapy with palliative doses. The motivation to employ SABR in a chemotherapy-refractory patient with a giant axillary mass was based on the high probability of controlling the disease and improving the symptoms. Our case report shows that ablative radiotherapy (SABR) should be a tool considered in palliative cancer management, once it brings several advantages such as: effective symptom control, sustained clinical response, short treatment time, and greater compliance.

Another peculiarity with the present case is the use of SABR in a large tumor. Generally, the use of SABR is limited to tumors around $5 \mathrm{~cm}$ due to the excessive risk of a large volume of normal tissue to be exposed to high radiation doses. Keeping this risk in mind, the SABR dose was calculated to respect the dose limit of the organs at risk around the tumor. A dose of 16Gy in a single fraction using $a / b=3$, would be equivalent to 60 Gy in 2 Gy fraction, which is a dose tolerable by the lung, skin, and chest wall.

Metastases, in any place, can generate pain and decrease the patients' quality of life. ${ }^{(8)}$ In such a situation,
(B)

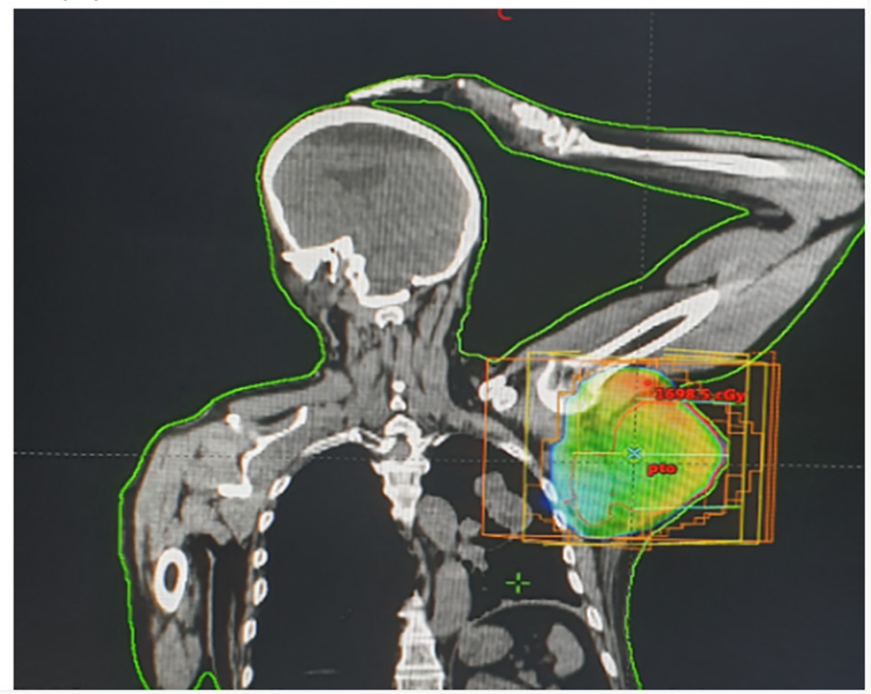

the tumor and symptoms control are vitally important, and SABR has considerable potential in producing a sustained clinical response. The sustained local control is a desirable endpoint even in a palliative scenario because it increases the chances of patients receiving more chemotherapy cycles without the inconvenience of chemotherapy interruptions or delays due to tumor complications as bleeding or infection.

In conclusion, this case report shows that SABR should be considered a treatment option in palliative care of selected patients with a large symptomatic tumor. The benefit observed here should be explored in further studies before SABR be adopted as the standard of care in this scenario.

\section{COMPETING INTERESTS}

The authors declare that they have no competing interests.

\section{FUNDING SOURCE}

None.

Authors' contributions

All authors participated the study design, data extraction, and analysis.

\section{REFERENCES}

1. Qaseem A, Usman N, Jayaraj JS, Janapala RN, Kashif T. Cancer of unknown primary: a review on clinical guidelines in the development and targeted management of patients with the unknown primary site. Cureus [Internet]. 2020 Sep; [cited 2020 Jul 8]; 11(9):e5552. Available from: https://www.ncbi.nlm. nih.gov/pmc/articles/PMC6820325/

2. Briasoulis $E$, Kalofonos H, Bafaloukos D, Samantas E, Fountzilas G, Xiros N, et al. Carboplatin plus paclitaxel in unknown primary carcinoma: a phase II Hellenic Cooperative Oncology Group Study. J Clin Oncol. 2000 Sep;18(17):3101-7. 
3. Greco FA, Rodriguez GI, Shaffer DW, Hermann R, Litchy S, Yardley DA, et al. Carcinoma of unknown primary site: sequential treatment with paclitaxel/ carboplatin/etoposide and gemcitabine/irinotecan: a Minnie Pearl Cancer Research Network phase II trial. Oncologist. 2004 Nov;9(6):644-52. DOI: https:// doi.org/10.1634/theoncologist.9-6-644

4. Palma DA, Olson R, Harrow S, Gaede S, Louie AV, Haasbeek C, et al. Stereotactic ablative radiotherapy versus standard of care palliative treatment in patients with oligometastatic cancers (SABR-COMET): a randomised, phase 2, open-label trial. Lancet. 2019 May;393(10185):2051-8.

5. Timmerman RD, Herman J, Cho LC. Emergence of stereotactic body radiation therapy and its impact on current and future clinical practice. J Clin Oncol. 2014 Sep;32(26):2847-54.
6. Kavanagh BD, McGarry RC, Timmerman RD. Extracranial radiosurgery (stereotactic body radiation therapy) for oligometastases. Semin Radiat Oncol. 2006 Apr;16(2):77-84.

7. Andratschke $N$, Alheid $H$, Allgäuer M, Becker G, Blanck O, Boda-Heggemann J, et al. The SBRT database initiative of the German Society for Radiation Oncology (DEGRO): patterns of care and outcome analysis of stereotactic body radiotherapy (SBRT) for liver oligometastases in 474 patients with 623 metastases. BMC Cancer. 2018 Mar;18(1):283.

8. Padilla GV, Presant C, Grant MM, Metter G, Lipsett J, Heide F. Quality of life index for patients with cancer. Res Nurs Health. 1983 Sep;6(3):117-26. DOI: https://doi.org/10.1002/nur.4770060305 